Article

\title{
Performance Improvement of Servo Control System Driven by Novel PMSM-DTC Based On Fixed Sector Division Criterion
}

\author{
Dazhi Wang ${ }^{1}$, Tianqing Yuan ${ }^{1, * \mathbb{D}}$, Xingyu Wang ${ }^{1}$, Xinghua Wang ${ }^{2}$ and Yongliang $\mathrm{Ni}^{3}$ \\ 1 School of Information Science and Engineering, Northeastern University, Shenyang 110819, China; \\ noblefuture@163.com (D.W.); wangxingyu@stumail.neu.edu.cn (X.W.) \\ 2 School of Humanities and Law, Northeastern University, Shenyang 110819,China; dm_wxy@126.com \\ 3 China North Vehicle Research Institute, Beijing 100072, China; 15210131012@163.com \\ * Correspondence: tqyuan@stumail.neu.edu.cn; Tel.: +86-133-2245-2013
}

Received: 22 May 2019; Accepted: 3 June 2019; Published: 5 June 2019

check for updates

\begin{abstract}
In order to improve the performance of the servo control system driven by a permanent magnet synchronous motor (PMSM) under novel direct torque control (NDTC), which, utilizing composite active vectors, fixed sector division criterion, is proposed in this paper. The precondition of the accurate compensations of torque and flux errors is that the sector where the stator flux linkage is located can be determined accurately. Consequently, the adaptive sector division criterion is adopted in NDTC. However, the computation burden is inevitably increased with the using of the adaptive part. On the other hand, the main errors can be compensated through SV-DTC (DTC-utilizing single active vector), while another active vector applied in NDTC can only supply the auxiliary error compensation. The relationships of the two active vectors' characteristics in NDTC are analyzed in this paper based on the active factor. Furthermore, the fixed sector division criterion is proposed for NDTC (FS-NDTC), which can classify the complexity of the control system. Additionally, the switching table for the selections of the two active vectors is designed. The effectiveness of the proposed FS-NDTC is verified through the experimental results on a 100-W PMSM drive system.
\end{abstract}

Keywords: servo control system; direct torque control (DTC); permanent magnet synchronous motor (PMSM); fixed sector division criterion; active factors

\section{Introduction}

A permanent magnet synchronous motor (PMSM) driven by direct torque control (DTC) has a lot of merits, including high reliability and good control performance. Therefore, it has been applied in industrial application widely [1-7]. Field-oriented control (FOC) and direct torque control are two widely applied high-performance control strategies for the PMSM [8-13]. Unlike the decoupled-analyzing method in FOC, torque and flux linkage are controlled directly in DTC, therefore, the quickest dynamic response can be obtained in the PMSM driven by DTC [14-16]. However, as only six active vectors can be selected to compensate the errors of flux linkage and torque in conventional DTC, the PMSM suffers from some drawbacks, such as large torque and flux linkage ripples [17-20].

The errors of torque and flux in the conventional PMSM-DTC system are compensated by a single active vector comprehensively, thus, the torque error and the flux error cannot be compensated accurately [1]. In this case, the error compensational strategy used in a conventional PMSM-DTC system can be called single vector error compensational strategy (SV-DTC). Furthermore, the torque vector and the flux vector are introduced into the PMSM-DTC system, and the novel direct torque control (NDTC) scheme is proposed [2], which can improve the steady-state performance of the PMSM 
effectively. Despite that a better performance of the PMSM driven by NDTC can be obtained, the computation burden is inevitably increased, due to the complexity of the control system.

The aim of this paper is to simplify the complexity of the servo control system by using a fixed sector division criterion. The relationships between the two active vectors' characteristics in NDTC are analyzed in this paper based on the active factor firstly. It should be noted that the main errors can be compensated by SV-DTC, and another active vector applied in NDTC can only supply the auxiliary error compensation. Therefore, the two active vectors applied in NDTC can be defined as master vector and slave vector, respectively.

Because the master vector can be selected based on SV-DTC, the precision of the slave vector selection is the key to determining the error compensational results. Therefore, the three-dimensional (3-D) diagram and the two-dimensional (2-D) contour map of the active factor are introduced to determine the suitable slave vector with the variation of the error rate and the sector location of the stator flux linkage. Furthermore, the fixed sector division criterion, including master sector and slave sector, is proposed for NDTC (FS-NDTC), which can classify the complexity of the control system effectively. Additionally, the switching table for the selections of the two active vectors is designed in this paper.

The rest of this paper comprises the following sections: The characteristics of the active factors are analyzed in Section 2. The suitable slave vectors with the variation of the error rate and the sector location of the stator flux linkage are described in Section 3. The characteristics of master vector and slave vector are also illustrated in Section 3. The fixed sector division criterion and the design of the switching table for master and slave vectors are given in Section 4. The description of the experimental setup and discussions on experimental results are given in Section 5 . The conclusion is analyzed in Section 6.

\section{Analysis of the Active Factors}

\subsection{Design of the Novel Switching Table Considering the Error Rate State}

In the proposed novel direct torque control (NDTC) scheme in [2], torque active vector and flux active vector are applied in one control period, as shown in Figure 1. It is also shown in Figure 1 that the proposed fixed sector division criterion is used to replace the adaptive sector division criterion.

As the main errors can be compensated by the applied active vector in SV-DTC [1], the two applied active vectors in NDTC can be classified as master vector (the applied active vector in SV-DTC) and slave vector (another applied active vector in NDTC).

The error rate state of the control system can be defined as

$$
\tau_{i}=\left\{\begin{array}{cc}
\tau_{0}<\tau<\frac{1}{\tau_{0}}, & i=\mathrm{A} \\
\tau<\tau_{0}, & i=\mathrm{B} \\
\tau>\frac{1}{\tau_{0}}, & i=\mathrm{C}
\end{array}\right.
$$

where $\tau_{0}$ is the reference value of error rate state.

The value of the error rate state is calculated as

$$
\tau=\frac{r_{\mathrm{T}}}{r_{\mathrm{F}}}
$$

where $r_{\mathrm{T}}$ and $r_{\mathrm{F}}$ are torque error rate and flux error rate, respectively, which can be obtained by

$$
\left[\begin{array}{c}
r_{\mathrm{T}} \\
r_{\mathrm{F}}
\end{array}\right]=\left[\begin{array}{cc}
\frac{1}{C_{\mathrm{T}}} & \\
& \frac{1}{C_{\mathrm{F}}}
\end{array}\right]\left[\begin{array}{l}
e_{\mathrm{T}} \\
e_{\mathrm{F}}
\end{array}\right]
$$

where $C_{\mathrm{T}}$ and $C_{\mathrm{F}}$ are the max compensations of torque error and flux error supplied by the active vector, respectively. 


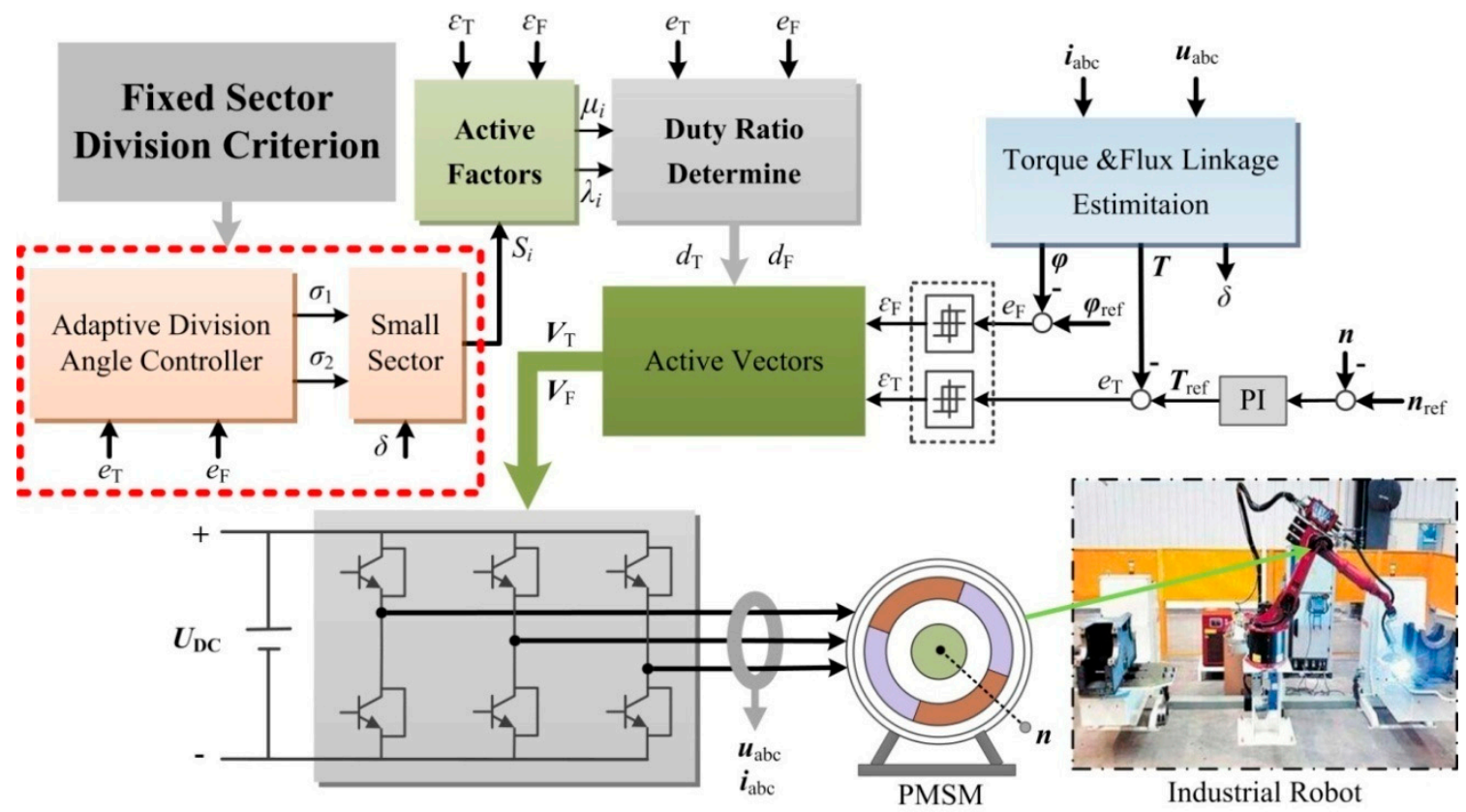

Figure 1. Schematic diagram of the novel direct torque control (NDTC) strategy for a permanent magnet synchronous motor (PMSM). Reproduced/Adapted with permission from [2], T, Q, Yuan, IEEE Access, T, Q, Yuan, 2019.

Therefore, the switching table of the active vectors in SV-DTC can be modified based on the value of the error rate state, as shown in Table 1.

Table 1. Vector switching table.

\begin{tabular}{|c|c|c|c|c|c|}
\hline Sector & Error Rate State & Error Property & $V_{\mathrm{n}}$ & Error Property & $V_{\mathrm{n}}$ \\
\hline \multirow{4}{*}{$S_{2+}$} & \multirow{2}{*}{$\tau_{\mathrm{A} / \mathrm{C}}$} & a & $V_{\mathrm{N}+1}$ & $\mathrm{~b}$ & $V_{\mathrm{N}+3}$ \\
\hline & & c & $V_{\mathrm{N}}$ & $\mathrm{d}$ & $V_{\mathrm{N}+4}$ \\
\hline & \multirow{2}{*}{$\tau_{\mathrm{B}}$} & a & $V_{\mathrm{N}+2}$ & $\mathrm{~b}$ & $V_{\mathrm{N}+2}$ \\
\hline & & c & $V_{\mathrm{N}+5}$ & d & $V_{\mathrm{N}+5}$ \\
\hline \multirow{2}{*}{$S_{1+}$} & \multirow{2}{*}{$\tau_{\mathrm{A} / \mathrm{B} / \mathrm{C}}$} & a & $V_{\mathrm{N}+1}$ & $\mathrm{~b}$ & $V_{\mathrm{N}+3}$ \\
\hline & & c & $V_{\mathrm{N}}$ & $\mathrm{d}$ & $V_{\mathrm{N}+4}$ \\
\hline \multirow{4}{*}{$S_{0}$} & \multirow{2}{*}{$\tau_{\mathrm{A} / \mathrm{B}}$} & $\mathrm{a}$ & $V_{\mathrm{N}+1}$ & $\mathrm{~b}$ & $V_{\mathrm{N}+2}$ \\
\hline & & c & $V_{\mathrm{N}+5}$ & d & $V_{\mathrm{N}+4}$ \\
\hline & \multirow{2}{*}{$\tau_{\mathrm{C}}$} & a & $V_{\mathrm{N}}$ & $\mathrm{b}$ & $V_{\mathrm{N}+3}$ \\
\hline & & c & $V_{\mathrm{N}}$ & d & $V_{\mathrm{N}+3}$ \\
\hline \multirow{2}{*}{$S_{1-}$} & \multirow{2}{*}{$\tau_{\mathrm{A} / \mathrm{B} / \mathrm{C}}$} & $\mathrm{a}$ & $V_{\mathrm{N}}$ & $\mathrm{b}$ & $V_{\mathrm{N}+2}$ \\
\hline & & c & $V_{\mathrm{N}+5}$ & d & $V_{\mathrm{N}+3}$ \\
\hline \multirow{4}{*}{$S_{2-}$} & \multirow{2}{*}{$\tau_{\mathrm{A} / \mathrm{C}}$} & a & $V_{\mathrm{N}}$ & $\mathrm{b}$ & $V_{\mathrm{N}+2}$ \\
\hline & & c & $V_{\mathrm{N}+5}$ & d & $V_{\mathrm{N}+3}$ \\
\hline & \multirow{2}{*}{$\tau_{\mathrm{B}}$} & a & $V_{\mathrm{N}+1}$ & $b$ & $V_{\mathrm{N}+1}$ \\
\hline & & c & $V_{\mathrm{N}+4}$ & $\mathrm{~d}$ & $V_{\mathrm{N}+4}$ \\
\hline
\end{tabular}

The error property in Table 1 is defined according to the values of torque error property and flux error property, as shown in Table 2. 
Table 2. Error property compound modes.

\begin{tabular}{ccc}
\hline Error Property & Torque Error Property & Flux Error Property \\
\hline $\mathrm{a}$ & 1 & 1 \\
$\mathrm{~b}$ & 1 & -1 \\
$\mathrm{c}$ & -1 & 1 \\
$\mathrm{~d}$ & -1 & -1 \\
\hline
\end{tabular}

\subsection{Analysis of the Characteristics for the Active Vectors}

The active angle and the impact angle of the one applied active vector in NDTC are $\theta_{\mathrm{s}}$ and $\delta_{\mathrm{s}}$ respectively, as shown in Figure 2.

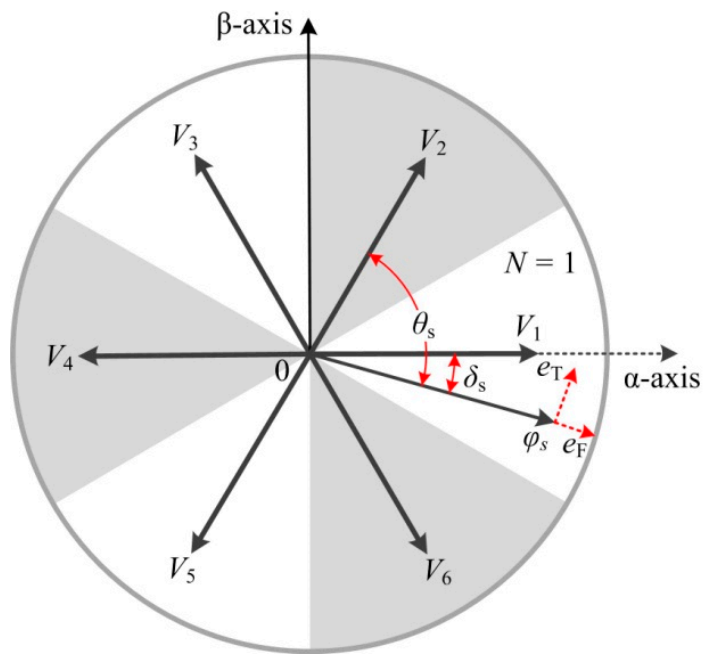

Figure 2. Relationships of the variables in the control system.

The active factors of torque error and flux error supplied by the applied active vector in Figure 1 can be calculated as

$$
\begin{aligned}
& \mu_{\mathrm{T}}=\sin \theta_{\mathrm{S}} \\
& \mu_{\mathrm{F}}=\cos \theta_{\mathrm{S}}
\end{aligned}
$$

In NDTC, the adaptive sector division criterion is adopted. Therefore, the active factors of the torque error and the flux error within different error rate states and different small sectors are shown in Table 3.

Table 3. Relationships among active factors and motor variables.

\begin{tabular}{ccccccc}
\hline \multirow{2}{*}{ Error Rate State } & \multicolumn{2}{c}{$\tau_{\mathbf{A}}$} & \multicolumn{2}{c}{$\tau_{\mathbf{B}}$} & \multicolumn{2}{c}{$\tau_{\mathbf{C}}$} \\
\cline { 2 - 7 } & $\mu_{\mathbf{T}}$ & $\mu_{\mathrm{F}}$ & $\mu_{\mathbf{T}}$ & $\mu_{\mathrm{F}}$ & $\mu_{\mathbf{T}}$ & $\mu_{\mathbf{F}}$ \\
\hline$S_{2+}$ & 0.5 & 0.9 & 1 & 0 & 0.5 & 0.9 \\
$S_{1+}$ & $(0.9,0.5)$ & $(0.5,0.9)$ & $(0.9,0.5)$ & $(0.5,0.9)$ & $(0.9,0.5)$ & $(0.5,0.9)$ \\
$S_{0}$ & 0.9 & 0.5 & 0.9 & 0.5 & 0 & 1 \\
$S_{1-}$ & $(0.5,0)$ & $(0.9,1)$ & $(0.5,0)$ & $(0.9,1)$ & $(0.5,0)$ & $(0.9,1)$ \\
$S_{2-}$ & 0.5 & 0.9 & 1 & 0 & 0.5 & 0.9 \\
\hline
\end{tabular}

With the using of different active vectors, the active factors, active angle, and the impact angle are binary periodic functions. In order to obtain the variation character of the active factors, the vector angle $\theta_{\mathrm{v}}$ that is between the applied active vector and the sector vector is introduced to replace the active angle. Therefore, the three-dimensional (3-D) diagram of $\mu_{\mathrm{T}}$ and $\mu_{\mathrm{F}}$ can be obtained, as shown 
in Figures $3 \mathrm{a}$ and $4 \mathrm{a}$. Furthermore, the two-dimensional contour map of the torque active factor and flux active factor are obtained by describing the third dimension, as shown in Figures $3 \mathrm{~b}$ and $4 \mathrm{~b}$.

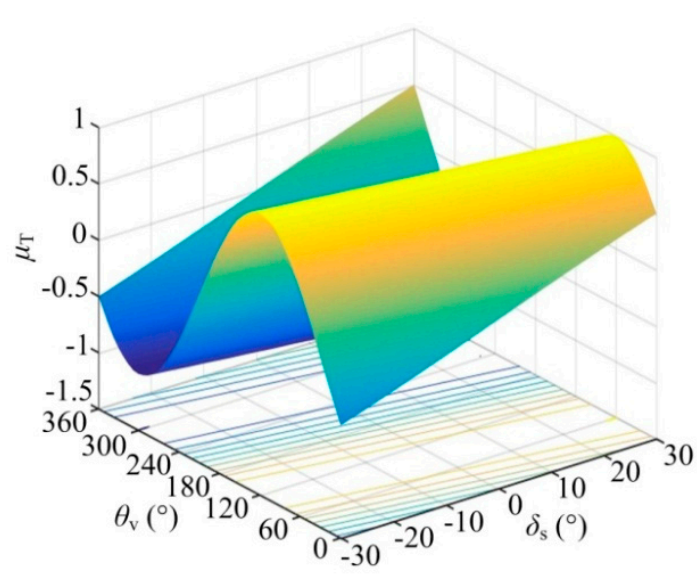

(a)

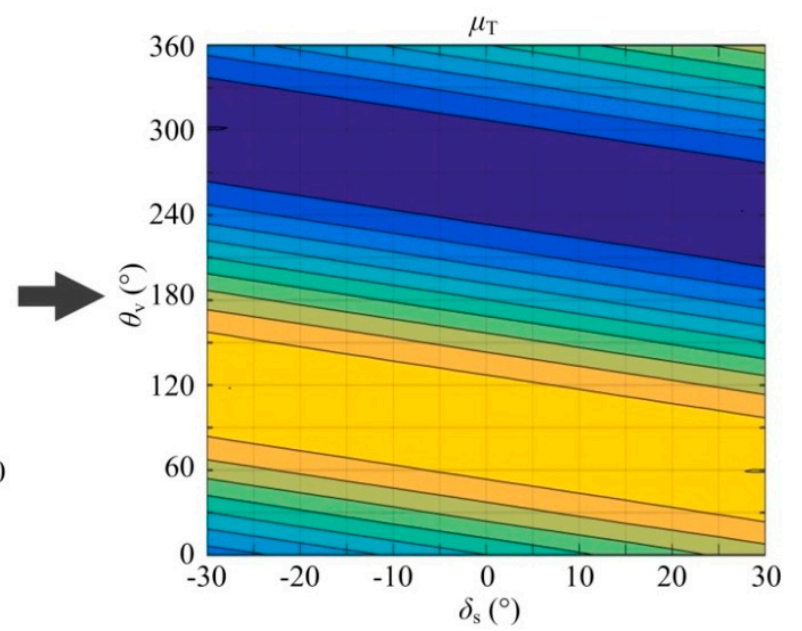

(b)

Figure 3. Torque active factor variation character. two-dimensional image.

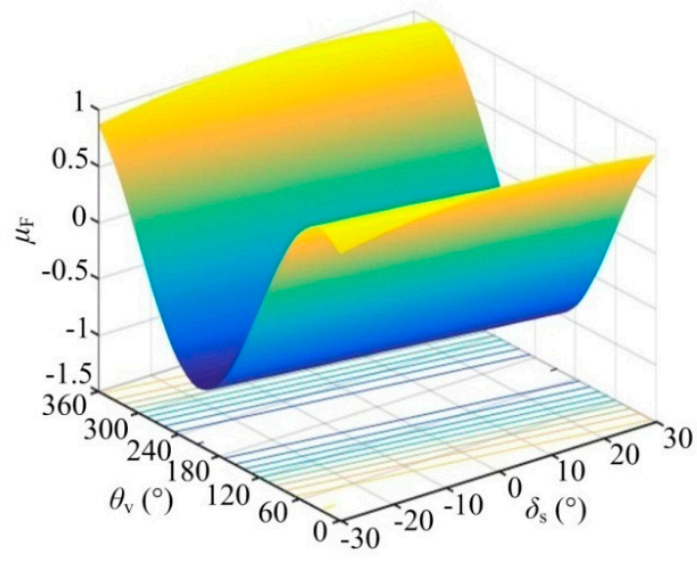

(a)

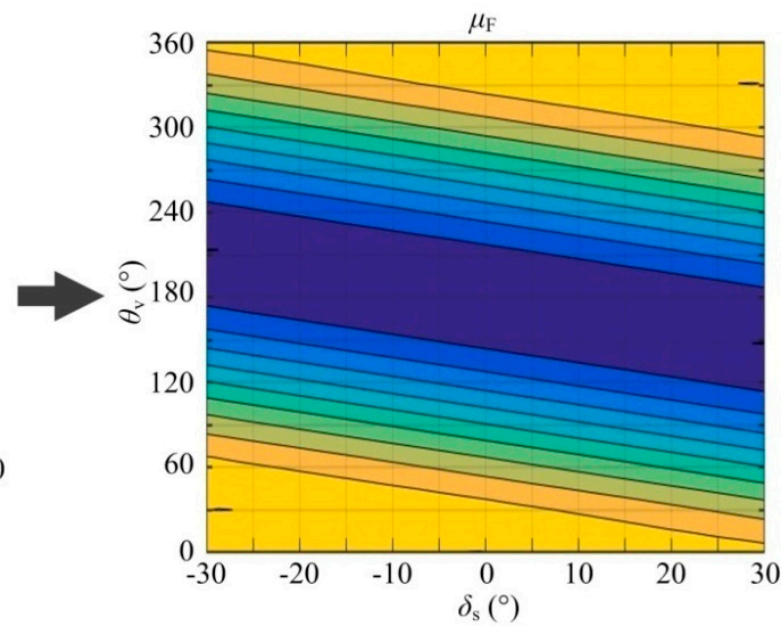

(b)

Figure 4. Flux active factor variation character. (a) three-dimensional image; (b) two-dimensional image.

\section{Analysis of the Suitable Slave Vectors with the Variation of the Variables}

\subsection{Slave Vectors Selection in Main Sector}

In SV-DTC, the suitable active vectors are $V_{2}$ or $V_{1}$, which can be applied to compensate the errors, while the stator flux linkage is located in $S_{1+}$ or $S_{1-}$ small sector. The vector angles of $V_{2}$ and $V_{1}$ are $60^{\circ}$ and $0^{\circ}$, respectively, as shown in Figure 5. 


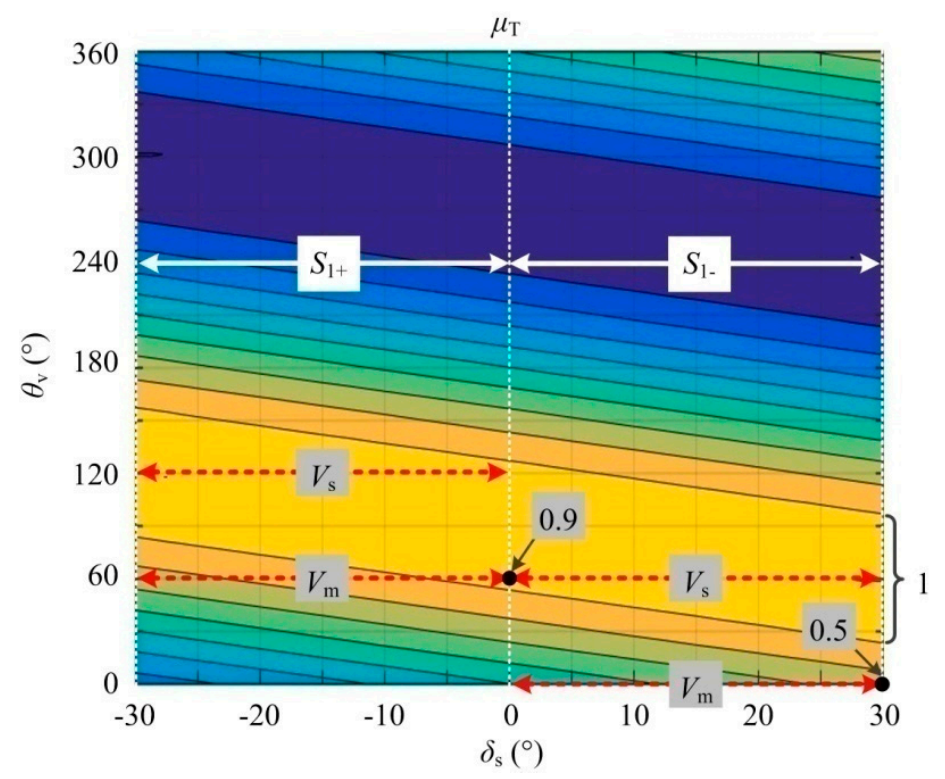

Figure 5. Two-dimensional contour map of torque error active factors.

(1) error rate state is $\tau_{\mathrm{B}}$

(a) $S_{1+}$ sector

Torque error is larger than flux error in the error rate state of $\tau_{\mathrm{B}}$. From Figure 5 , it can be observed that the max value of torque active factor supplied by the master vector $V_{2}$ is 0.9 with the impact changing from $-30^{\circ}$ and $0^{\circ}$.

In order to compensate the large torque error effectively, the active vector $V_{3}$, which supplied the best torque active factor, should be selected as the slave vector, and its vector angle is $120^{\circ}$.

(b) $S_{1-}$ sector

It is also shown in Figure 5 that the max value of torque active factor of the master vector $V_{1}$ is only 0.5 , with the impact changing from $0^{\circ}$ and $30^{\circ}$. Therefore, the active vector $V_{2}$, which supplied the best torque active factor, should be selected as the slave vector to compensate the large torque error effectively, and its vector angle is $60^{\circ}$.

(2) error rate state is $\tau_{\mathrm{C}}$

(a) $S_{1+}$ sector

The flux error is larger than the torque error in the error rate state of $\tau_{C}$. From Figure 6 , it can be observed that the wanted flux active factor cannot be supplied by the master vector $V_{2}$ with the impact changing from $-30^{\circ}$ and $0^{\circ}$.

In order to meet the required large flux error compensations, the active vector $V_{1}$, which supplied the best flux active factor, should be selected as the slave vector to compensate the large flux error effectively, and its vector angle is $0^{\circ}$.

(b) $S_{1-}$ sector

It is also shown in Figure 6 that master vector $V_{1}$ can supply larger flux error compensations. To avoid the offset of the error compensations, the active vector $V_{6}$, which supplied the positive flux active factor, should be selected as the slave vector, and its vector angle is $300^{\circ}$.

(3) error rate state is $\tau_{\mathrm{A}}$

(a) $S_{1+}$ sector

The stator flux linkage is located in $S_{1+}$, and the torque active factor and the flux active factor are equal, so the relationships of the variables can be described as

$$
\mu_{\mathrm{T}}=\sin \theta_{\mathrm{s} 2}=\mu_{\mathrm{F}}=\cos \theta_{\mathrm{s} 2}
$$


The impact angle can be obtained as

$$
\delta_{\mathrm{s} 2}=\theta_{\mathrm{s} 2}-60^{\circ}=-15^{\circ}
$$

Figure 7 shows that the value of the torque active factor supplied by the master vector $V_{2}$ is the balance value of 0.7 , while the impact angle is $-15^{\circ}$. In addition, the torque error compensation will become smaller with the impact angle changing from $-15^{\circ}$ to $-30^{\circ}$. Therefore, the active vector $V_{3}$ should be selected as the slave vector, which can supply the decreased torque error compensation supplied by the master vector $V_{2}$.

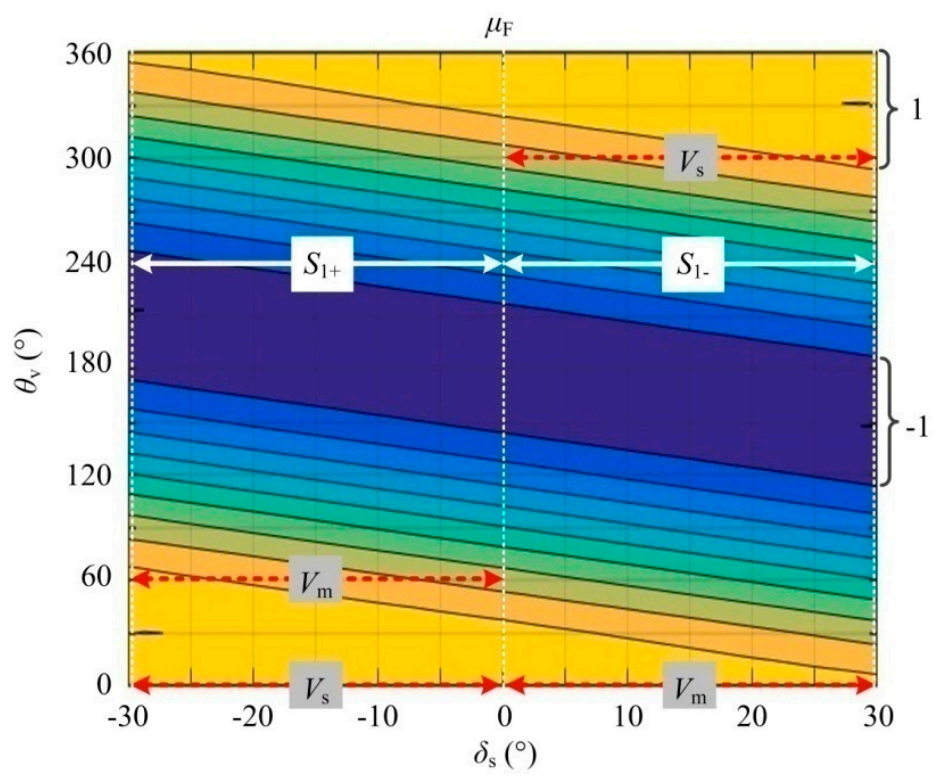

Figure 6. Two-dimensional contour map of flux error active factors.

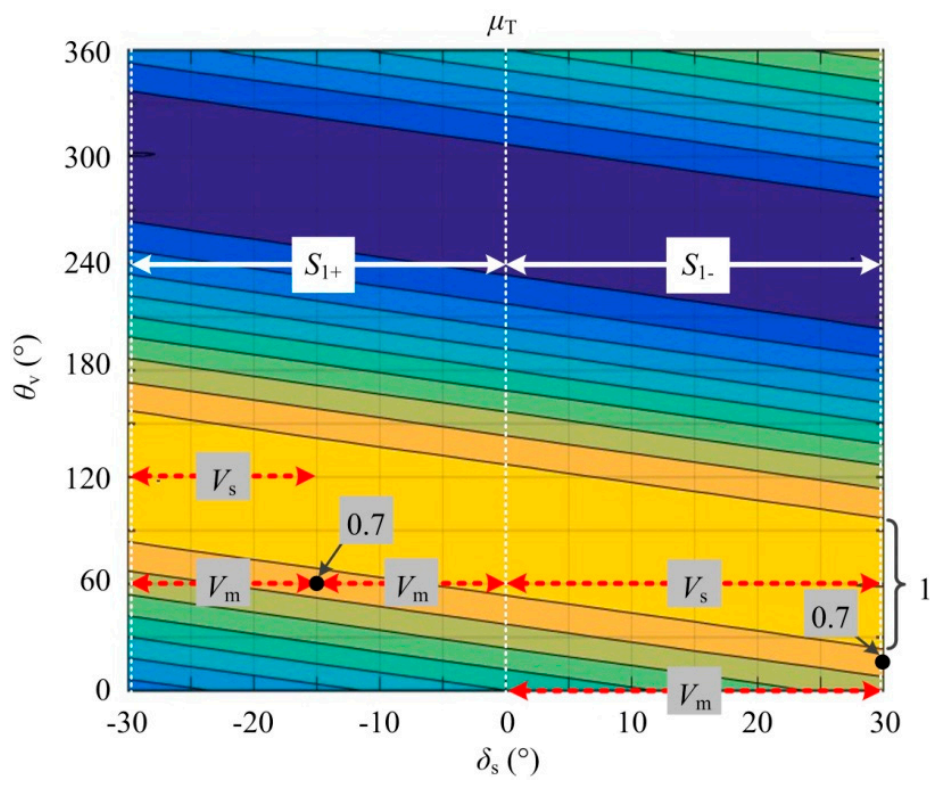

Figure 7. Two-dimensional contour map of torque error active factors.

According to the two-dimensional contour map of the torque active factor in Figure 7, it can be observed that the value of the torque active factor supplied by the master vector $V_{2}$ is the balance value of 0.7 , while the impact angle is $-15^{\circ}$. In addition, the torque error compensation will become smaller 
with the impact angle changing from $-15^{\circ}$ to $-30^{\circ}$. Therefore, the active vector $V_{3}$ should be selected as the slave vector, which can supply the decreased torque error compensation supplied by the master vector $V_{2}$.

According to the two-dimensional contour map of the flux active factor in Figure 8, it can be observed that the value of flux active factor supplied by the master vector $V_{2}$ is the balance value of 0.7 , while the impact angle is $-15^{\circ}$. Consequently, the flux error compensation will become smaller with the impact angle changing from $-15^{\circ}$ to $0^{\circ}$. In this case, the active vector $V_{1}$ should be selected as the slave vector, which can supply the decreased flux error compensation supplied by the master vector $V_{2}$.

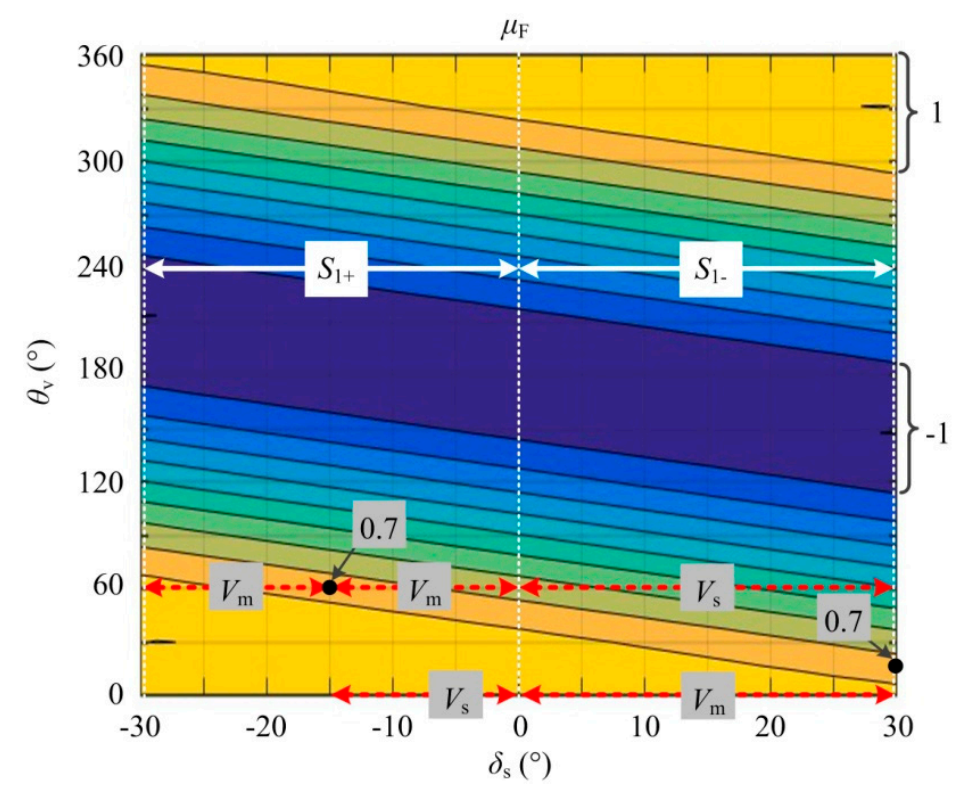

Figure 8. Two-dimensional contour map of flux error active factors.

(b) $S_{1-\text { sector }}$

When the stator flux linkage is located in $S_{1-}$ sector, the variation range of the impact angle is from $0^{\circ}$ to $30^{\circ}$. The comparison result of the torque active factor and the flux active factor supplied by the master vector $V_{1}$ can be expressed as

$$
\mu_{\mathrm{T}}<\mu_{\mathrm{F}}
$$

According to the two-dimensional contour maps of the torque active factor and flux active factor in Figures 7 and 8, it can be observed that the value of the torque active factor supplied by $V_{1}$ is constantly lower than the balance value 0.7 , while the value of the flux active factor is constantly greater than the balance value 0.7 . Thus, $V_{2}$ is the most suitable active vector to be the slave vector, considering the torque error and the flux error compensational results synthetically.

\subsection{Slave Vectors Selection in Other Sectors}

(1) $S_{0}$ sector

(a) The active vector $V_{2}$ will be selected as the master vector while the error rate state is $\tau_{\mathrm{A}}$. According to the two-dimensional contour map of the flux active factor in Figure 9, it can be observed that the value of the flux active factor supplied by the master vector $V_{2}$ is constantly lower than the balance value of 0.7 . Therefore, in order to compensate the motor errors, the active vector $V_{1}$ should be selected as the slave vector, which can supply the flux error compensation supplied by the master vector $V_{2}$. 


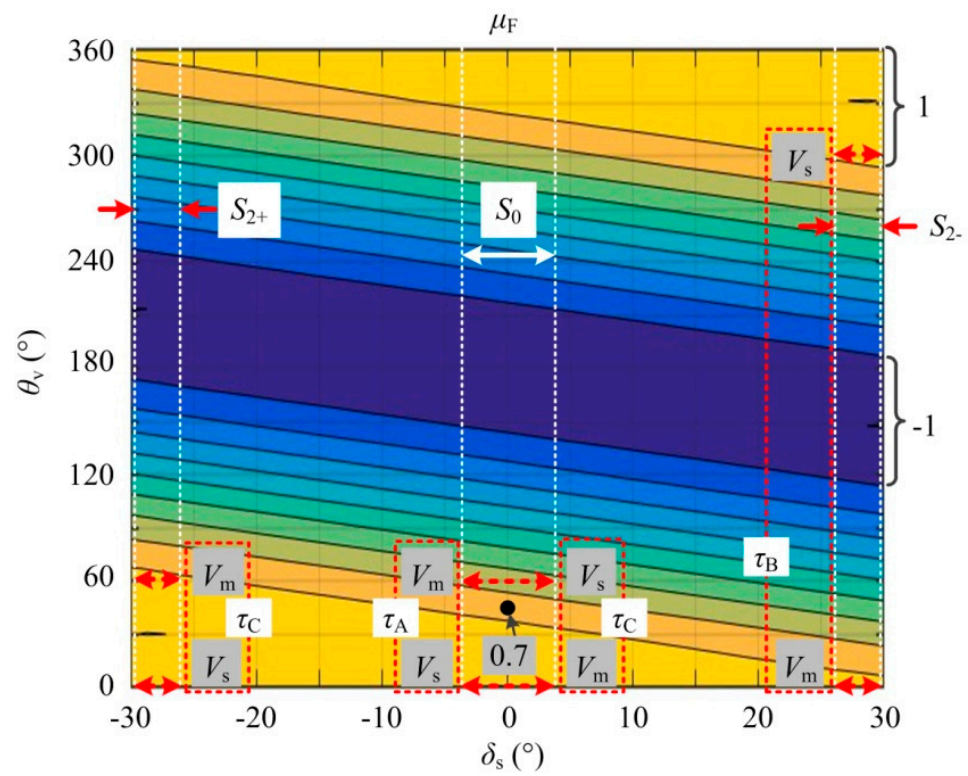

Figure 9. Two-dimensional contour map of flux error active factors.

(b) The active vector $V_{2}$ will be selected as the master vector while the error rate state is $\tau_{\mathrm{B}}$. According to the two-dimensional contour map of the torque active factor in Figure 10, it can be observed that the master vector $V_{2}$ can supply the large torque error compensation. The torque error is much greater than the flux error in the error rate state of $\tau_{\mathrm{B}}$, therefore, the active vector $V_{3}$ that can supply the greatest torque error compensation should be selected as the slave vector.

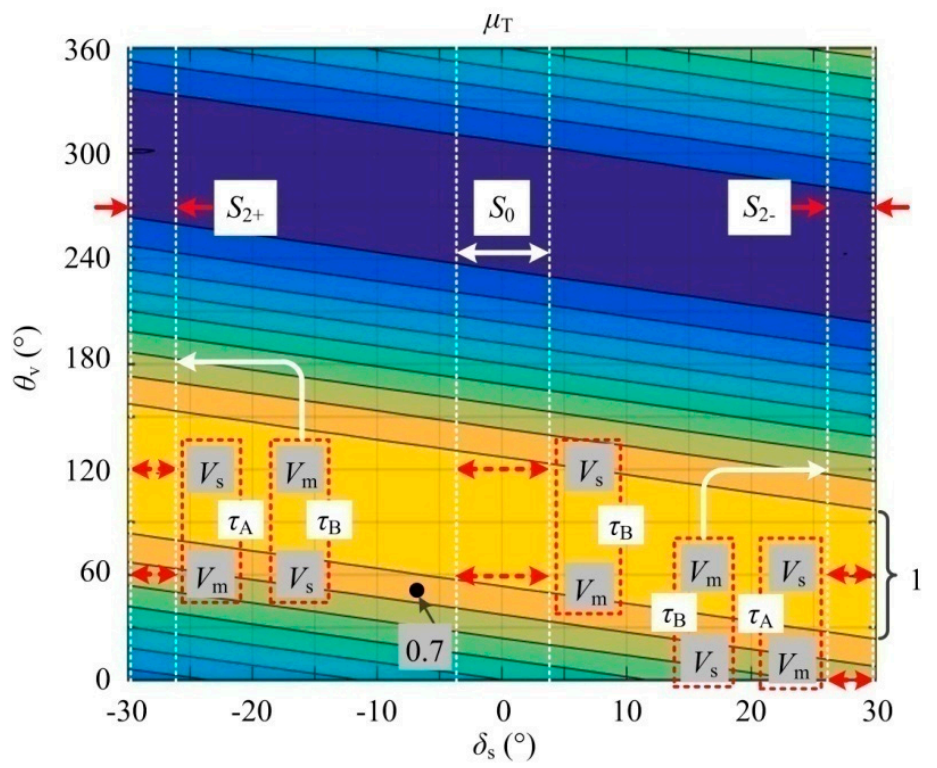

Figure 10. Two-dimensional contour map of torque error active factors.

(c) The active vector $V_{1}$ will be selected as the master vector while the error rate state is $\tau_{\mathrm{C}}$. According to the two-dimensional contour map of the flux active factor in Figure 9, it can be observed that the master vector $V_{1}$ can supply the greatest flux error compensation. The flux error is much greater than the torque error in the error rate state of $\tau_{C}$, therefore, the active vector $V_{2}$ that can supply the positive flux error compensation should be selected as the slave vector to avoid the offset of the flux error compensations supplied by different active vectors.

(2) $S_{2+}$ sector 
(a) The active vector $V_{2}$ will be selected as the master vector while the error rate state is $\tau_{\mathrm{A}}$. According to the two-dimensional contour map of the torque active factor in Figure 10, it can be observed that the value of the torque active factor supplied by the master vector $V_{2}$ is constantly lower than the balance value 0.7 . Therefore, the active vector $V_{1}$ should be selected as the slave vector, which can supply the insatiable torque error compensation supplied by the master vector $V_{2}$, which can compensate the motor errors effectively.

(b) The active vector $V_{3}$ will be selected as the master vector while the error rate state is $\tau_{\mathrm{B}}$. According to the two-dimensional contour map of the torque active factor in Figure 10, it can be observed that the master vector $V_{3}$ can supply the greatest torque error compensation. The torque error is much greater than the flux error in the error rate state of $\tau_{\mathrm{B}}$, therefore, the active vector $V_{2}$ that can supply the positive torque error compensation should be selected as the slave vector to avoid the offset of the torque error compensations supplied by different active vectors.

(c) The active vector $V_{2}$ will be selected as the master vector while the error rate state is $\tau_{C}$. According to the two-dimensional contour map of the flux active factor in Figure 9, it can be observed that the master vector $V_{2}$ can supply a large flux error compensation. The flux error is much greater than the torque error in the error rate state of $\tau_{\mathrm{C}}$, hence, the active vector $V_{1}$ that can supply much greater flux error compensation should be selected as the slave vector.

(3) $S_{2-}$ sector

(a) The active vector $V_{1}$ is selected as the master vector while the error rate state is $\tau_{\mathrm{A}}$. According to the two-dimensional contour map of the torque active factor in Figure 10, it can be observed that the value of torque active factor supplied by $V_{1}$ is constantly lower than the balance value 0.7 . Therefore, the active vector $V_{2}$ should be selected as the slave vector, which can supply much greater torque error compensation.

(b) The active vector $V_{2}$ will be selected as the master vector while the error rate state is $\tau_{\mathrm{B}}$. According to the two-dimensional contour map of torque active factor in Figure 10, it can be observed that the master vector $V_{2}$ can supply the greatest torque error compensation. The torque error is much greater than the flux error in the error rate state of $\tau_{\mathrm{B}}$, therefore, the active vector $V_{1}$ that can supply the positive torque error compensation should be selected as the slave vector to avoid the offset of the torque error compensations supplied by different active vectors.

(c) The active vector $V_{1}$ will be selected as the master vector while the error rate state is $\tau_{C}$. According to the two-dimensional contour map of the flux active factor in Figure 9, it can be observed that the master vector $V_{1}$ can supply the large flux error compensation. The flux error is much greater than the torque error in the error rate state of $\tau_{C}$, hence, the active vector $V_{6}$ that can also supply the large flux error compensation should be selected as the slave vector.

\subsection{Analysisthe Characteristics of the Master and Slave Vectors}

From the aforementioned analyses, it can be observed that the suitable master vector and slave vector are different with the variation of the error rate state and the sector where the stator flux linkage is located. Table 4 shows the conclusions of the suitable master vector and slave vector for different variations of PMSM.

Table 4. Relationships among active factors and motor variables.

\begin{tabular}{ccccccc}
\hline \multirow{2}{*}{ Error Rate State } & \multicolumn{2}{c}{$\tau_{\mathbf{A}}$} & \multicolumn{2}{c}{$\tau_{\mathbf{B}}$} & \multicolumn{2}{c}{$\tau_{\mathbf{C}}$} \\
\cline { 2 - 7 } & $\boldsymbol{V}_{\mathbf{m}}$ & $\boldsymbol{V}_{\mathbf{s}}$ & $\boldsymbol{V}_{\mathbf{m}}$ & $\boldsymbol{V}_{\mathbf{s}}$ & $\boldsymbol{V}_{\mathbf{m}}$ & $V_{\mathbf{s}}$ \\
\hline$S_{2+}$ & $V_{2}$ & $V_{3}$ & $V_{3}$ & $V_{2}$ & $V_{2}$ & $V_{1}$ \\
$S_{1++}$ & $V_{2}$ & $V_{3}$ & $V_{2}$ & $V_{3}$ & $V_{2}$ & $V_{1}$ \\
$S_{1+-}$ & $V_{2}$ & $V_{1}$ & $V_{2}$ & $V_{3}$ & $V_{2}$ & $V_{1}$ \\
$S_{0}$ & $V_{2}$ & $V_{1}$ & $V_{2}$ & $V_{3}$ & $V_{1}$ & $V_{2}$ \\
$S_{1-}$ & $V_{1}$ & $V_{2}$ & $V_{1}$ & $V_{2}$ & $V_{1}$ & $V_{6}$ \\
$S_{2-}$ & $V_{1}$ & $V_{2}$ & $V_{2}$ & $V_{1}$ & $V_{1}$ & $V_{6}$ \\
\hline
\end{tabular}


There exists no difference with the applied sequence variation of master vector and slave vector. Therefore, the characteristics of the suitable active vector in each small sector can be described as:

(1) The selected master and slave vectors are the same, while the stator flux linkage is located in $S_{2+}$ or $S_{1++}$ sector;

(2) The selected master and slave vectors are the same, while the stator flux linkage is located in $S_{0}$ or $S_{1+-}$ sector;

(3) The selected master and slave vectors are the same, while the stator flux linkage is located in $S_{2-}$ or $S_{1-}$ sector.

In short, the small sectors $S_{2+}, S_{0}$ and $S_{2-}$ are not necessary. Furthermore, the adaptive sector division criterion is not suitable for NDTC.

\section{Design of Master and Slave Vectors' Switching Table}

\subsection{Devision of Master and Slave Sectors}

The negative sector and the positive sector in each sector in conventional DTC are defined as master sector and slave sector, respectively. The slave sector can be divided into the positive slave sector and the negative slave sector through the median line $l_{\mathrm{m}+}$, according to the Equation (7).

The location of the master sector and the slave sector will exchange equally, therefore, the master sector should also be divided into the positive master sector and the negative master sector through the median line $l_{\mathrm{m}-}$. The analysis results of the sector characteristic for sector 1 is shown in Figure 11 .

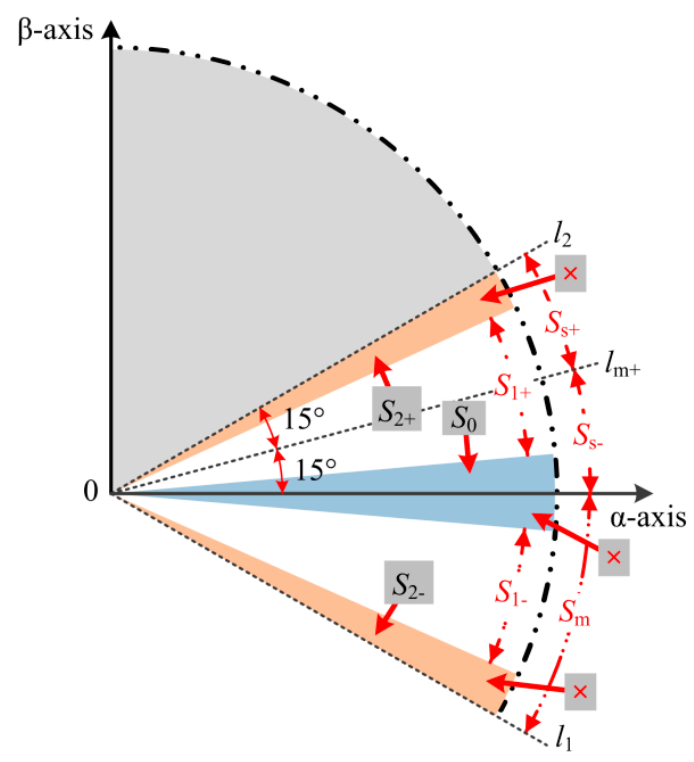

Figure 11. Relationships of the variables in the control system.

According to the analysis results in Figure 10, the division criterion for the master and slave sector, which is suitable for NDTC, can be obtained in terms of the active vector that is closest to the error, as shown in Figure 12. 


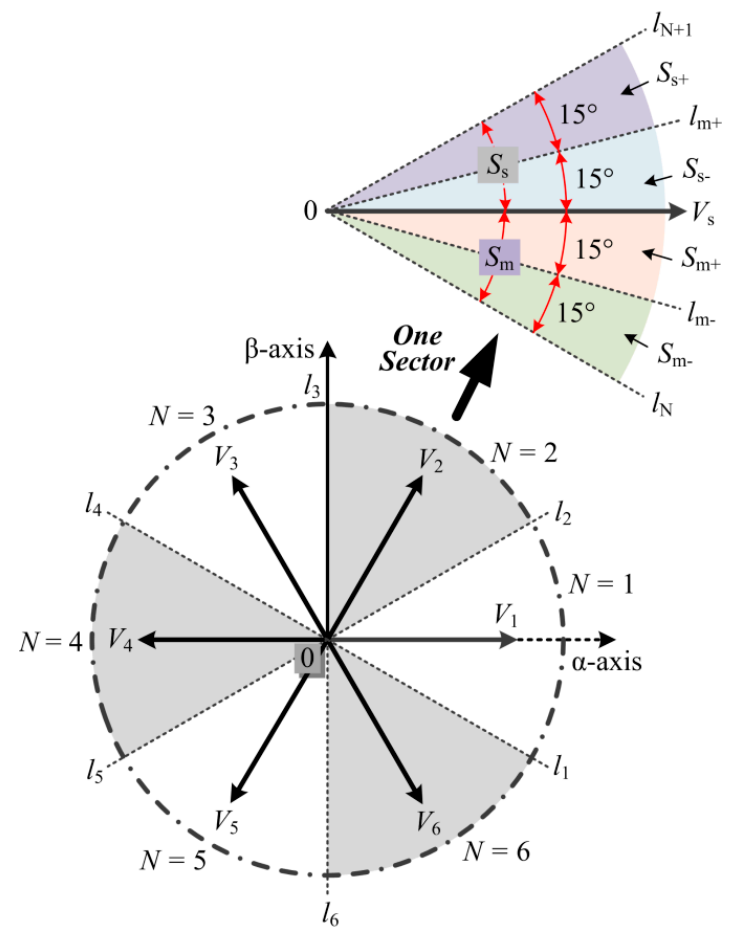

Figure 12. Fixed sector division results.

\subsection{Master and Slave Vectors Switching Table}

The slave vector is applied to compensate the errors that the master vector cannot compensate, therefore, the master vector switching table is the same in SV-DTC, and the slave vector switching table that considers the error rate state is shown in Table 5.

Table 5. Slave vector switching table.

\begin{tabular}{|c|c|c|c|c|c|}
\hline$\tau_{i}$ & Sector & Error Property & $V_{\mathrm{s}}$ & Error Property & $V_{\mathrm{s}}$ \\
\hline \multirow{8}{*}{$\tau_{\mathrm{A}}$} & \multirow{2}{*}{$S_{\mathrm{s}+}$} & $\mathrm{a}$ & $V_{\mathrm{N}+2}$ & $\mathrm{~b}$ & $V_{\mathrm{N}+2}$ \\
\hline & & c & $V_{\mathrm{N}+5}$ & d & $V_{\mathrm{N}+5}$ \\
\hline & \multirow{2}{*}{$S_{\text {s- }}$} & a & $V_{\mathrm{N}}$ & $\mathrm{b}$ & $V_{\mathrm{N}+2}$ \\
\hline & & c & $V_{\mathrm{N}+5}$ & d & $V_{\mathrm{N}+5}$ \\
\hline & \multirow{2}{*}{$S_{\mathrm{m}+}$} & $\mathrm{a}$ & $V_{\mathrm{N}+1}$ & $\mathrm{~b}$ & $V_{\mathrm{N}+1}$ \\
\hline & & c & $V_{\mathrm{N}}$ & d & $V_{\mathrm{N}+4}$ \\
\hline & \multirow{2}{*}{$S_{\mathrm{m}-}$} & a & $V_{\mathrm{N}+1}$ & $\mathrm{~b}$ & $V_{\mathrm{N}+1}$ \\
\hline & & c & $V_{\mathrm{N}+4}$ & d & $V_{\mathrm{N}+4}$ \\
\hline \multirow{4}{*}{$\tau_{\mathrm{B}}$} & \multirow{2}{*}{$S_{\mathrm{s}}$} & $\mathrm{a}$ & $V_{\mathrm{N}+2}$ & $\mathrm{~b}$ & $V_{\mathrm{N}+2}$ \\
\hline & & c & $V_{\mathrm{N}+5}$ & d & $V_{\mathrm{N}+5}$ \\
\hline & \multirow{2}{*}{$S_{\mathrm{m}}$} & $\mathrm{a}$ & $V_{\mathrm{N}+1}$ & $\mathrm{~b}$ & $V_{\mathrm{N}+1}$ \\
\hline & & c & $V_{\mathrm{N}+4}$ & d & $V_{\mathrm{N}+4}$ \\
\hline \multirow{4}{*}{$\tau_{\mathrm{C}}$} & \multirow{2}{*}{$S_{\mathrm{s}}$} & $\mathrm{a}$ & $V_{\mathrm{N}}$ & $\mathrm{b}$ & $V_{\mathrm{N}+4}$ \\
\hline & & c & $V_{\mathrm{N}+1}$ & d & $V_{\mathrm{N}+3}$ \\
\hline & \multirow{2}{*}{$S_{\mathrm{m}}$} & $\mathrm{a}$ & $V_{\mathrm{N}+5}$ & $\mathrm{~b}$ & $V_{\mathrm{N}+3}$ \\
\hline & & c & $V_{\mathrm{N}}$ & $\mathrm{d}$ & $V_{\mathrm{N}+2}$ \\
\hline
\end{tabular}

\section{Experimental Analysis}

\subsection{Experimental System Setup}

Experimental studies are carried out on a 100-W PMSM drive system to validate the effectiveness of the fixed sector division criterion for NDTC (FS-NDTC). The experimental hardware setup is 
illustrated in Figure 13. The parameters of the PMSM are given as follows: $R_{s}=0.76 \Omega ; L_{S}=0.00182 \mathrm{H}$; the number of pole pairs $p=4$. The DC voltage is $36 \mathrm{~V}$. The rated speed and torque are $750 \mathrm{rpm}$ and $1.2 \mathrm{Nm}$, respectively. This study compares the steady-state and the dynamic response performance of the PMSM, driven by FS-NDTC and NDTC. The experiments are implemented in a TMS320F28335 DSP control system with a sampling period of $100 \mu \mathrm{s}$.

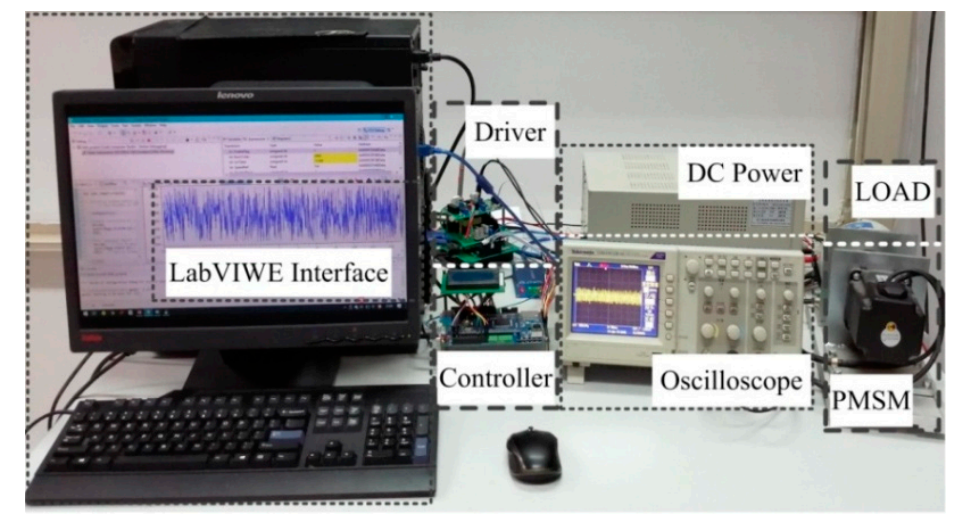

Figure 13. Experimental setup of control system.

\subsection{Steady-State Performance}

The steady-state performances of FS-NDTC and NDTC are compared under the same operating conditions. The PMSM is operated at $500 \mathrm{rpm}$ and the reference values of torque and flux linkage are $0.8 \mathrm{Nm}$ and $0.3 \mathrm{~Wb}$, respectively. The torque and flux linkage waveforms of the PMSM driven by NDTC and FS-NDTC are shown in Figure 14a,b, respectively.
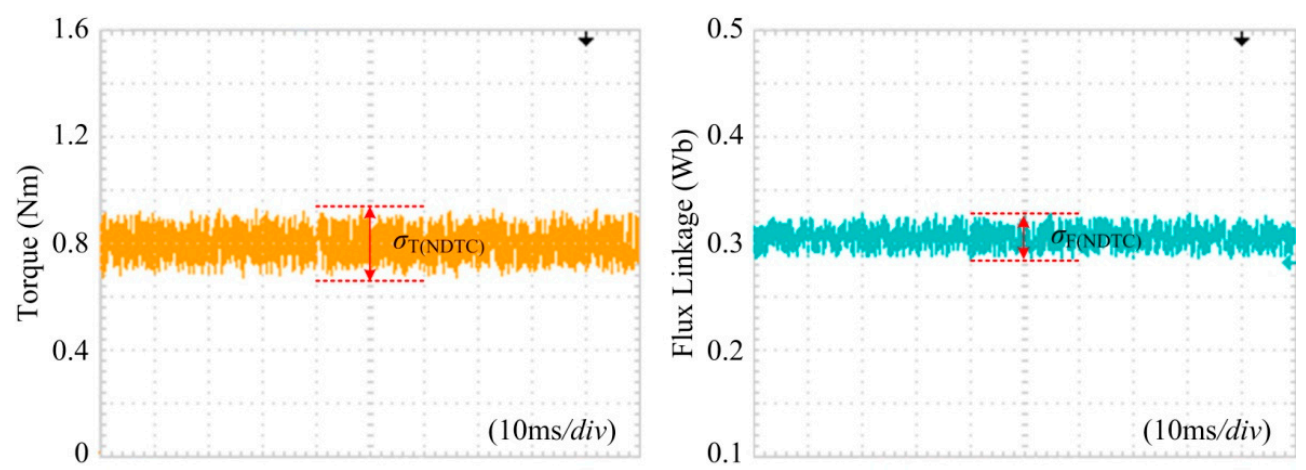

(a)
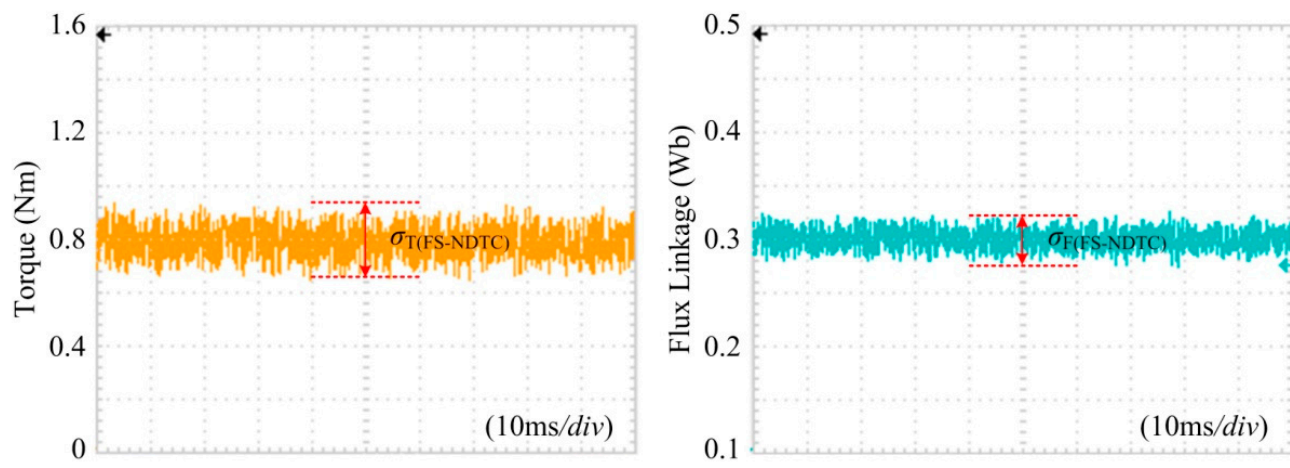

(b)

Figure 14. Experimental torque and flux linkage of the PMSM when using: (a) NDTC; (b) FS-NDTC.

From these experimental results, it can be found that the torque ripples and the flux linkage ripples of NDTC are $0.32 \mathrm{Nm}$ and $0.035 \mathrm{~Wb}$, respectively. The torque ripples and the flux linkage 
ripples of FS-NDTC are $0.32 \mathrm{Nm}$ and $0.045 \mathrm{~Wb}$, respectively. Therefore, although the proposed fixed sector division criterion classify the complexity of NDTC, the ideal steady-state performance in NDTC will not be affected with the using of a fixed sector division criterion.

\subsection{Dynamic Performance}

To validate the fast dynamic response of the proposed FS-NDTC, the speed and torque responses of the PMSM driven by the two control strategies are tested. In the speed tests, a step change from 200 to $400 \mathrm{rpm}$ is applied on the speed reference when the torque is set as $0.5 \mathrm{Nm}$. The speed waveforms of the PMSM driven by NDTC and FS-NDTC are as shown in Figure 15a,b, respectively.

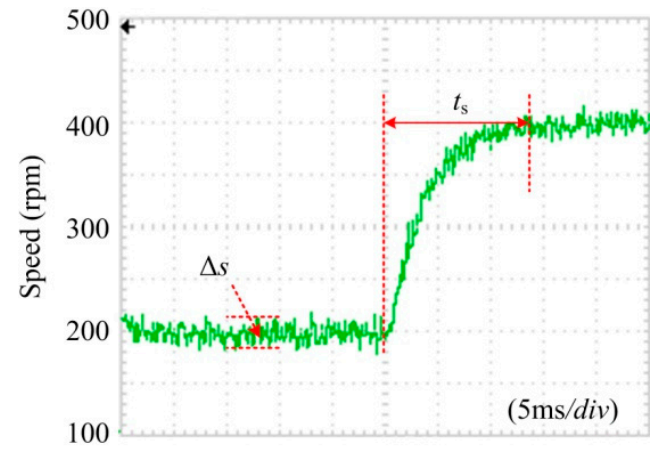

(a)

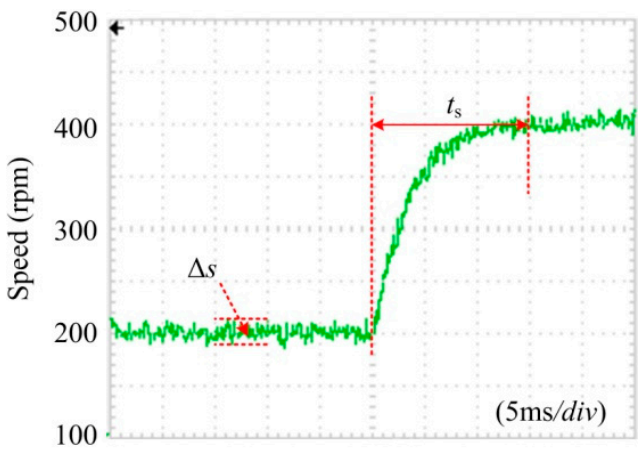

(b)

Figure 15. The speed trajectory is from $200 \mathrm{rpm}$ to $400 \mathrm{rpm}$ when using: (a) NDTC; (b) FS-NDTC.

In the torque and flux linkage tests, a step change from 0 to $100 \mathrm{rpm}$ is applied on the speed reference when the torque and the flux linkage are set as $0.5 \mathrm{Nm}$ and $0.3 \mathrm{~Wb}$, respectively. The torque and flux linkage waveforms of the PMSM driven by NDTC and FS-NDTC are as shown in Figure $16 a, b$, respectively.

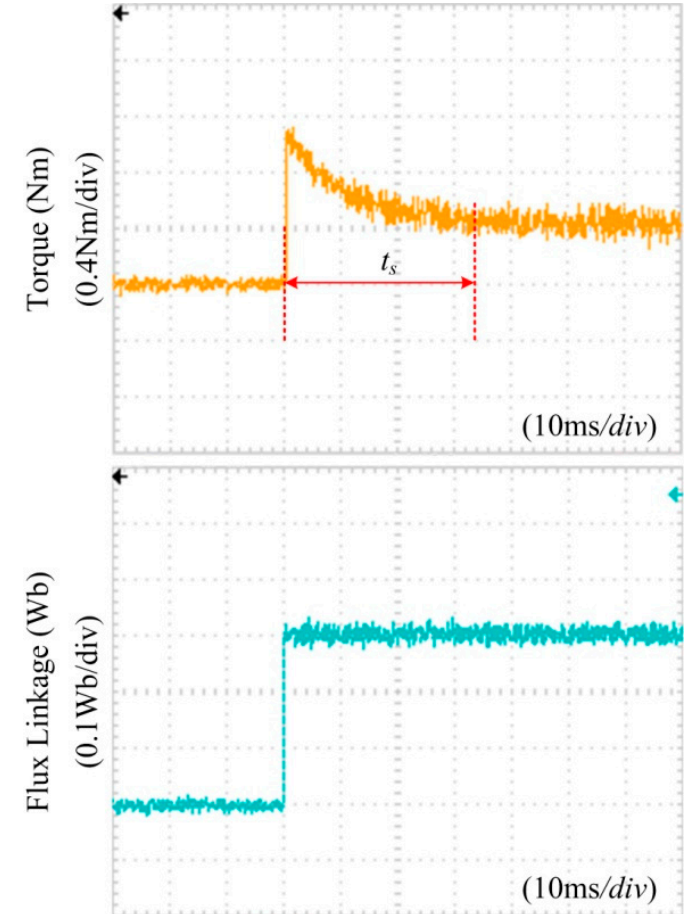

(a)

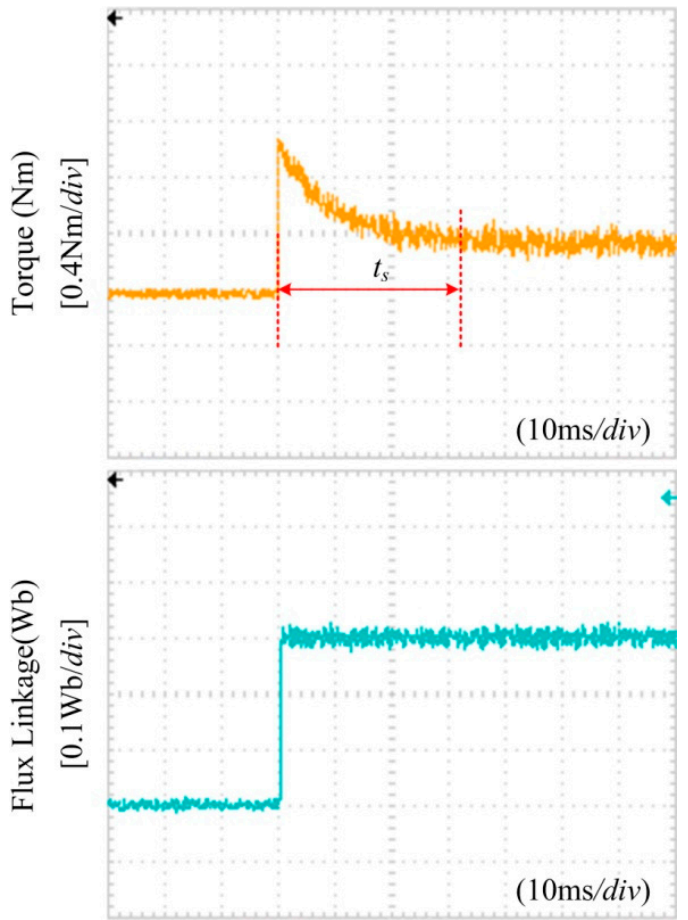

(b)

Figure 16. The torque and flux linkage trajectory when using: (a) NDTC; (b) FS-NDTC. 
From the above tests, it can be seen that the ripples of the rotor speed with the using of NDTC and FS-NDTC are 29 and $27 \mathrm{rpm}$, respectively. Moreover, the settling time of the rotor speed using the two different control strategies are 0.014 and $0.015 \mathrm{~s}$. In the torque and flux linkage tests, it can be seen that the flux linkage can adjust to the settling value within an instant, and the settling times of the torque using the two different control strategies are 0.034 and $0.032 \mathrm{~s}$.

Therefore, the main advantage of NDTC, i.e., the fast dynamic response, is maintained in FS-NDTC. The experimental results show that dynamic response owns higher priority than ripples in dynamic-state condition, hence, the adaptive sector division criterion can be abandoned.

\section{Conclusions}

The fixed sector division criterion is introduced to replace the adaptive sector division criterion used in NDTC in this paper. The proposed fixed sector division criterion can simplify the determination process of the sector where the stator flux linkage is located. To ensure the reasonability of the fixed sector division criterion, the active factors of the applied active vectors are used to obtain the characteristic relationships of the master vector and the slave vector in NDTC. Finally, the switching table for the slave vector is designed, which can ensure the required error compensational results, using the proposed fixed sector division criterion.

Experimental results clearly indicate that the FS-NDTC exhibits similar control performance of torque and flux linkage when compared to NDTC, and the transient response performance can also be retained in FS-NDTC. In short, the steady and dynamic performances of the PMSM driven by NDTC and FS-NDTC are similar. The proposed fixed sector division criterion can simplify the complexity of the servo control system without decreasing the operation performance of the PMSM.

Author Contributions: This paper was a collaborative effort between the authors. T.Y., D.W., X.W., X.W., and Y.N. proposed the original idea; T.Y. wrote the full manuscript and carried out the experiments.

Acknowledgments: This work was supported by National Key Research and Development Program of China under Grant 2017YFB1300900.

Conflicts of Interest: The authors declare there is no conflict of interest.

\section{References}

1. Yuan, T.Q.; Wang, D.Z.; Li, Y.L. Duty ratio modulation strategy to minimize torque and flux linkage ripples in IPMSM DTC system. IEEE Access 2017, 5, 14323-14332. [CrossRef]

2. Yuan, T.Q.; Wang, D.Z.; Wang, X.H. High-Precision servo control of industrial robot driven by PMSM-DTC utilizing composite active vectors. IEEE Access 2019, 7, 7577-7587. [CrossRef]

3. Abosh, A.; Zhu, Z.Q.; Ren, Y. Reduction of torque and flux ripples in space vector modulation-based direct torque control of asymmetric permanent magnet synchronous machine. IEEE Trans. Power Electron. 2017, 32, 2976-2986. [CrossRef]

4. Zhou, Y.Z.; Chen, G.T. Predictive DTC Strategy with fault-tolerant function for six-phase and three-phase PMSM series-connected drive system. IEEE Trans. Ind. Electron. 2018, 65, 9101-9112.

5. Shinohara, A.; Inoue, Y.; Morimoto, S.; Sanada, M. Direct calculation method of reference flux linkage for maximum torque per ampere control in DTC-based IPMSM drives. IEEE Trans. Power Electron. 2016, 32, 2114-2122.

6. Alsofyani, I.M.; Idris, N.R.N.; Lee, K.B. Dynamic hysteresis torque band for improving the performance of lookup-table-based DTC of induction machines. IEEE Trans. Power Electron. 2018, 33, 7959-7970. [CrossRef]

7. Putri, A.K.; Rick, S.; Franck, D.; Hameyer, K. Application of sinusoidal field pole in a permanent-magnet synchronous machine to improve the NVH behavior considering the MTPA and MTPV operation area. IEEE Trans. Ind. Appl. 2016, 52, 2280-2288. [CrossRef]

8. Xia, C.; Zhao, J.; Yan, Y.; Shi, T. A novel direct torque and flux control method of matrix converter-fed PMSM drives. IEEE Trans. Power Electron. 2014, 29, 5417-5430. [CrossRef] 
9. Mohan, D.; Zhang, X.; Foo, G.H.B. A simple duty cycle control strategy to reduce torque ripples and improve low-speed performance of a three-level inverter fed DTC IPMSM drive. IEEE Trans. Ind. Electron. 2017, 64, 2709-2721.

10. Niu, F.; Wang, B.; Babel, A.S.; Li, K.; Strangas, G.E. Comparative evaluation of direct torque control strategies for permanent magnet synchronous machines. IEEE Trans. Power Electron. 2016, 31, 1408-1424.

11. Zhang, Y.; Zhu, J.; Xu, W.; Guo, Y. A simple method to reduce torque ripple in direct torque-controlled permanent-magnet synchronous motor by using vectors with variable amplitude and angle. IEEE Trans. Ind. Electron. 2011, 58, 2848-2859.

12. Ren, Y.; Zhu, Z.Q.; Liu, J. Direct torque control of permanent-magnet synchronous machine drives with a simple duty ratio regulator. IEEE Trans. Ind. Electron. 2014, 61, 5249-5258.

13. Niu, F.; Li, K.; Wang, Y. Direct torque control for permanent magnet synchronous machines based on duty ratio modulation. IEEE Trans. Ind. Electron. 2015, 62, 6160-6170.

14. Lee, J.S.; Lorenz, R.D. Deadbeat direct torque and flux control of IPMSM drives using a minimum time ramp trajectory method at voltage and current limits. IEEE Trans. Ind. Appl. 2014, 50, 3795-3804. [CrossRef]

15. Mohan, D.; Zhang, X.; Foo, G. Generalized DTC strategy for multilevel inverter fed IPMSMs with constant inverter switching frequency and reduced torque ripples. IEEE Trans. Energy Convers. 2017, 32, 1031-1041. [CrossRef]

16. ZL, X.N.; Foo, G.H.B. Over-modulation of constant switching frequency based DTC for reluctance synchronous motors incorporating field-weakening operation. IEEE Trans. Ind. Electron. 2019, 66, 37-47.

17. Berzoy, A.; Rengifo, J.; Mohammed, O. Fuzzy predictive DTC of induction machines with reduced torque ripple and high performance operation. IEEE Trans. Power Electron. 2018, 33, 2580-2587. [CrossRef]

18. Choi, Y.-S.; Choi, H.H.; Jung, J.W. Feedback linearization direct torque control with reduced torque and flux ripples for IPMSM drives. IEEE Trans. Power Electron. 2016, 31, 3728-3737. [CrossRef]

19. Zhang, Z.; Wei, C.; Qiao, W.; Qu, L. Adaptive saturation controller-based direct torque control for permanent-magnet synchronous machines. IEEE Trans. Power Electron. 2016, 31, 7112-7122. [CrossRef]

20. Liang, D.L.; Li, J.; Qu, R.H.; Kong, W.B. Adaptive second-order sliding-mode observer for PMSM sensorless control considering VSI nonlinearity. IEEE Trans. Power Electron. 2018, 33, 8994-9004. [CrossRef]

(C) 2019 by the authors. Licensee MDPI, Basel, Switzerland. This article is an open access article distributed under the terms and conditions of the Creative Commons Attribution (CC BY) license (http://creativecommons.org/licenses/by/4.0/). 